\title{
Política econômica brasileira frente à crise mundial recente: uma análise baseada nas contribuições de Kaldor
}

Joanílio Rodolpho Teixeira, Danielle Sandi Pinheiro e Paula Felix Ferreira*

\section{Introdução}

O artigo de Kaldor (1971), "Conflicts in National Economic Objectives", é um estudo seminal para a compreensão das tensões sobre variáveis macroeconômicas no processo de estabelecer metas e instrumentos da busca de resultados para a política econômica. As preocupações de Kaldor sobre as dificuldades da economia britânica no final da década de 1960 decorriam, principalmente, de considerações sobre técnicas e estratégias inapropriadas de gestão que priorizavam o crescimento liderado pelo consumo em vez de liderado pelas exportações ${ }^{1}$. A combinação dessas duas abordagens está presente no tratamento histórico dos problemas da economia brasileira e também daqueles mais recentes causados pela crise econômica internacional.

A versão original da teoria kaldoriana prioriza o crescimento do PIB, impulsionado pelo aumento das exportações. Estas são dependentes do aumento da renda mundial e da possibilidade de alcançar saldos na balança comercial. O processo envolve especialmente a diversificação na pauta de exportações industriais, 
o que depende de investimentos produtivos tanto para sustentar o crescimento do setor como para atrair investimentos domésticos e externos, além de incorporar o progresso tecnológico. As exportações são um componente exógeno da demanda agregada que desempenha um papel fundamental.

Os países que atuam no ensejo de implementar essa concepção macroeconômica buscam ampliar investimentos no setor industrial, alcançar avanços no progresso tecnológico para expandir a produtividade e assim atender a novos mercados. A estratégia kaldoriana está sujeita a um debate teórico e empírico, pois a implementação dessa agenda envolve um "pacote de medidas" de políticas industrial, monetária e fiscal. Nesse sentido, busca-se revigorar o setor industrial, medidas essas que nem sempre estão em sintonia com a teoria estática (ricardiana) das vantagens comparativas. A abordagem envolve uma perspectiva dinâmica, e, para se testar a mesma, têm sido utilizadas diversas versões no modelo de Thirwall (1979), em que a elasticidaderenda da demanda por importações é obtida pela razão entre a taxa de crescimento das exportações e a taxa de crescimento do produto. Uma versão recente contempla aspectos multissetoriais e dinâmicos do modelo, conforme salientam Teixeira e Araújo (2012).

Naturalmente, para um bom desempenho industrial, é necessário prestar atenção em:

i) reduzir as incertezas do mercado por meio de normativas consistentes e transparentes;

ii) estimular a eficiência na troca de informações entre os agentes públicos e privados, externos e internos;

iii) gerar uma política de câmbio que favoreça o setor industrial; iv)buscar uma política de juros com baixa rentabilidade do investimento especulativo, privilegiando assim o empreendedorismo produtivo; e

v) reduzir os custos de transação, estimulando assim a integração "forward" e "backward"da cadeia produtiva.

Críticos da abordagem kaldoriana sugeriram, na época, mudanças no modelo. Posteriormente, foi sugerido um new development paradigm, no caso, domestic demandled growth. Este se baseava na abordagem que privilegiava o crescimento impulsionado pela expansão da demanda interna, e não apenas o consumo. Nesse contexto, policy makers buscariam desenvolver esforços no sentido de evitar a dependência exagerada do comércio externo - a base do modelo export-led growth. Isso exigiria uma guinada de direção da visão governamental, almejando desprender-se das condições impostas pelo investidor e o mercado externo.

Hoje em dia, os governantes não têm vislumbrado uma ruptura completa entre os dois modelos, mas sim uma diferença de ênfase dentro de uma totalidade econômica. Com efeito, busca-se atualmente uma síntese do enfoque doméstico e do enfoque exportador, ao contrário de uma rivalidade entre pensamentos opostos. Outro olhar sobre o problema consiste em visualizar duas versões alternativas: uma baseada no regime de crescimento wage-led (quando um aumento da participação da massa salarial na renda nacional gera impacto positivo no crescimento) e a outra no profit-led (quando esse aumento dos salários gera um impacto negativo). Na perspectiva de estratégias de crescimento, uma questão relevante consiste em determinar empiricamente qual tipo de regime de crescimento vigora em determinada economia. Contudo, esse é um problema que envolve a distribuição funcional da renda, ganhos de produtividade 
e questões políticas contingentes ao momento histórico. Portanto, não se pode garantir uma conclusão unívoca sobre o sucesso das estratégias em questão. Nossa inclinação é pela validade condicional e reexame da abordagem kaldoriana original (export-led versus consumption-led growth), uma vez que acreditamos que esse enfoque possui um arsenal teórico mais compatível com fatos estilizados da realidade nos países emergentes. A saber, a perspectiva da distribuição funcional da renda na versão convencional é do tipo jogo-somazero, em que as perdas se equivalem aos ganhos - o que não tem ocorrido no Brasil. Nossa preferência de consumption-versusexporté condicional, pois percebermos que não necessariamente a estratégia baseada na demand-led growth implica automaticamente a acomodação da oferta à demanda. Esse tema escapa ao escopo do presente trabalho ${ }^{2}$.

Destaca-se no trabalho de Kaldor a teoria circular de causação acumulativa (circular cumulative causation) ${ }^{3}$. Esta sintetiza uma investigação dinâmica em que diversas variáveis são analisadas simultaneamente, uma vez que suas relações são interligadas. Nessa perspectiva, como há grande interdependência entre as variáveis macroeconômicas, Kaldor sugere quatro variáveis simultâneas essenciais para analisar o desempenho macroeconômico: taxa de crescimento da economia, taxa de desemprego, taxa de inflação e balanço de pagamentos como percentagem do PIB.

Diversos economistas e policy makers perceberam que os instrumentos acima não são necessariamente associados a fundamentos teóricos ou conceituais de contextos específicos, mas consistem em um conjunto de propostas operacionais de ampla validade. Nesse sentido, Karl Schiller, Ministro das Finanças da
Alemanha Ocidental entre 1971 e 1972, introduziu uma representação gráfica conhecida como quadrado mágico, que operacionalizava geometricamente as ideias de Kaldor. Com pequenas modificações, essa análise visual ganhou destaque internacional em estudos e publicações da OCDE. Bernard et alii (1988) sumarizam a utilização desse instrumento de análise para a comparação do desempenho econômico pré-crise no período 1960-1973 e durante a crise no

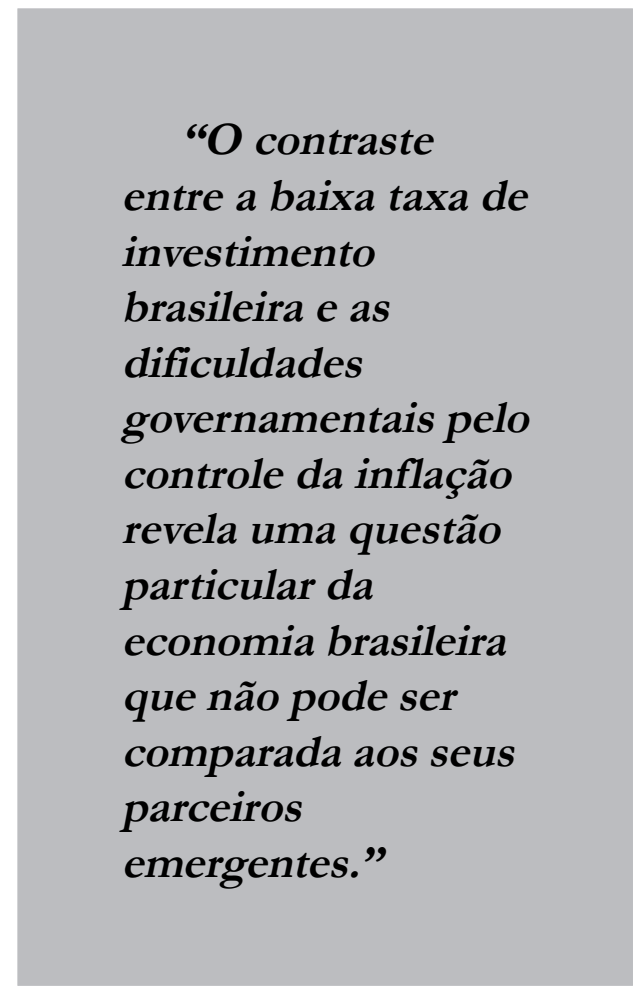

período 1974-1980 na França, Japão e Inglaterra.

Medrano-B e Teixeira (2012), em trabalho fundamentalmente teórico, revisitaram a construção dos quadrados mágicos buscando mensurar o impacto de políticas econômicas. Nesse sentido, eles estenderam a construção gráfica original incorporando uma análise algébrica que quantifica a 
geometria envolvida na elaboração desse instrumento de avaliação macroeconômica.

No presente texto, buscamos utilizar parte do instrumental analítico reformulado (quadrados mágicos) para estudar o impacto da crise recente a partir de dados da economia brasileira nos períodos 20072008 e 2009-2010. A abordagem é conectada com a concepção kaldoriana centrada no debate export-led versus consumption-led growth mencionado. $\mathrm{Na}$ parte empírica, fazemos um diagnóstico período por período (antes e durante a crise) para a economia brasileira.

Após essa introdução, na seção seguinte apresentamos elementos da concepção teórica, representação geométrica e contribuição analítica dos quadrados mágicos com os indicadores econômicos para o Brasil (Gráfico 1), indicadores relacionados a políticas econômicas implementadas em razão da crise (Gráfico 2) e também revisitamos o debate kaldoriano sobre crescimento sustentado pelas exportações ou impulsionado pelo consumo. Em seguida, consideramos, especificamente, metas e instrumentos utilizados nos dois períodos. Por fim, são apresentadas as conclusões, em que salientamos que a complexidade da gestão macroeconômica tem sido subestimada.

\section{O quadrado mágico modificado com representação da perspectiva kaldoriana}

Desde os esforços iniciais para se entender a crise de 2008, surgiram muitas análises acerca de seu impacto no Brasil. Nesse contexto, também se levantaram questões acerca da efetividade das medidas brasileiras sequencialmente adotadas. $\mathrm{O}$ desempenho de nossa economia pode ser medido via estudos econométricos, pela construção de modelos matemáticos, ou pela simples análise gráfica. Naturalmente, é possível analisar tais performances e os conflitos nas metas e instrumentos de política macroeconômica utilizando a abordagem de Kaldor (1971), que sintetiza uma investigação em que diversas variáveis são analisadas simultaneamente, uma vez que suas relações são interligadas. Como há grande interdependência entre as mesmas, é interessante introduzir a visualização geométrica na forma do quadrado mágico. Tal abordagem pode ser estendida em diversas direções. Na Tabela 1, são apresentados os dados para a economia nos períodos relevantes para a análise proposta:

Tabela 1: Dados para o quadrado de Kaldor (médias dos períodos)

\begin{tabular}{l|c|l}
\hline & $\mathbf{2 0 0 7 - 0 8}$ & $\mathbf{2 0 0 9 - 1 0}$ \\
\hline Inflação & 5,18 & 4,81 \\
\hline PIB & 5,63 & 3,6 \\
\hline Desemprego & 8,55 & 7,4 \\
\hline Transações Correntes & $-0,803$ & $-1,863$ \\
\hline
\end{tabular}

Fonte: dados Ipeadata.

No presente trabalho, no intuito de se construir o quadrado mágico, os valores para a economia brasileira, com base na Tabela 1, têm os seguintes campos de validade ${ }^{4}$ :

$\sigma-$ Crescimento $(-2 \leq \sigma \leq 8)$

$\pi$ - Inflação (IPCA) $(2 \leq \pi \leq 7)$

$\varphi$ Transações correntes $(-2 \leq \varphi \leq 2)$

$\delta$ - Desemprego $(5 \leq \delta \leq 10)$

Esses valores de referência surgiram da necessidade de se modelar um país Wonderland (ideal), que teria seus indicadores otimizados, com base em uma transformação linear dos campos de validade. Os valores-limite do espaço amostral surgiram das amplitudes máximas e 
mínimas obtidas pelo Brasil na última década, de forma a circunscrever o país "perfeito" kaldoriano ao limiar de uma representação realista. $O$ desemprego inicia o seu espaço amostral a partir de 5\% pela suposição de que os governos não estariam interessados em reduzir esse índice para zero.

Para tal argumentação é útil trazer as palavras de Kalecki:

"É falsa a suposição de que um governo manterá o pleno emprego numa economia capitalista se ele sabe como fazê-lo. Com relação a isso, é de crucial importância a desconfiança dos grandes empresários acerca da manutenção do pleno emprego por meio do gasto governamental (Kalecki, 1977, p.54).”

As palavras de Kalecki suscitam uma questão difícil e fascinante que pode decorrer de três visões: i) reprovação à interferência pura e simples do governo no problema do emprego, utilizando gastos públicos; ii) reprovação ao direcionamento da despesa governamental que pode gerar crowding-out (investimento público afastando investimento privado) em vez de crowdingin (investimento público estimulando investimento privado); e iii) os capitalistas tendem a rejeitar o pleno emprego decorrente do déficit orçamentário do governo que poderia gerar inflação (isto é, uma espiral viciosa de preços e salários). Esse processo só faria sentido se fosse possível evitar inflação. Portanto, é necessário não forçar exageradamente o dispêndio público acima daquilo que for considerado uma utilização adequada do trabalho e dos bens de capital. Além dos gastos suscitados pelo contínuo déficitorçamentário na sustentação do pleno emprego, há a recusa dos empresários em perder seu poder de barganha que determina o mark-up (KALECKI, 1944).
Retomando a perspectiva do quadrado de Kaldor, com relação aos "quadrângulos" internos, indicados no Gráfico 1, quanto menores as respectivas áreas, menor a performance de um país. Com o propósito de verificar quais foram as principais estratégias estabelecidas e quais foram as respostas da política macroeconômica, tendo como referência a crise internacional, foi construído o quadrado mágico normalizado. Ele trata das mudanças entre os períodos pré-crise (média 2007-2008) e após deflagração da recessão mundial (média no período 2009-2010).

Para uma análise gráfica correta, como reconsiderada por Medrano-B e Teixeira (2012), tivemos que rever as unidades dimensionais que estão sendo abordadas. Nesse sentido, selecionamos um índice que vai de 0 a 100, de modo que a seleção de uma constante numérica (100) possa normalizar a unidade da área. Esse novo índice adimensional pode ser visualizado da seguinte maneira:

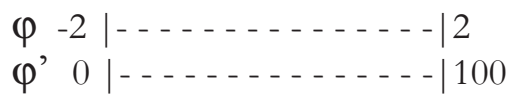

Percebe-se, na Figura 1, que qualquer ponto no eixo $\varphi$ ' pode corresponder a um ponto no eixo $\varphi$. Isso nos possibilita responder o problema de descobrir a reta relevante:

Figura 1: Normalização dos indicadores

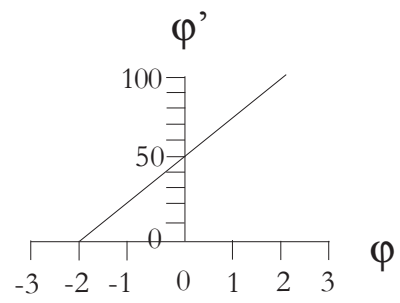

Fonte: Elaboração própria. 
Nesse caso, $\varphi^{\prime}=25(\varphi+2)$.

Analogamente, a partir de um índice de 0 a 100, temos:

$$
\begin{aligned}
& \pi^{\prime}=20 \pi-40 \\
& \sigma^{\prime}=10 \sigma+20 \\
& \delta^{\prime}=20 \delta-100
\end{aligned}
$$

Com base nas expressões algébricas acima, para , $\varphi^{\prime}, \pi$ ', $\sigma^{\prime}$ e $\delta$ ' além dos indicadores da Tabela 1 , podemos construir o quadrado mágico normalizado, como no Gráfico 1 (ver página seguinte).

Percebem-se aqui os impactos gerais da crise: a retração da atividade econômica como um todo, evidenciada por meio de uma abrupta queda na taxa de crescimento do PIB, um déficit nas transações correntes e relativa estabilidade no nível de emprego. A inflação permaneceu sob controle, em face da baixa demanda doméstica e internacional. Via de regra, pode-se afirmar que o País sofreu um baque com o novo cenário externo, mas as medidas de política econômica adotadas pelo Governo em resposta e a manutenção de um mercado interno relativamente fortalecido garantiram que o País não entrasse em prolongada recessão. Contudo, as políticas adotadas não foram capazes de impedir contrações significativas na taxa de crescimento e o resultado negativo das transações correntes.

Em um novo quadrado mágico baseado nos dados da Tabela 2, propomos uma análise embasada em variáveis macroeconômicas diretamente relacionadas às políticas aplicadas em razão da crise.

Com isso, é possível interpretar por outro ângulo como foi a atuação governamental diante da crise e as respostas da economia no que se refere aos indicadores das finanças públicas. Para essa análise foram selecionadas quatro variáveis ${ }^{5}$ : $\alpha$ - Operações de crédito ao setor público e privado $(\% \mathrm{PIB}) \quad 0 \leq \alpha \leq 60$ $\beta$ - Taxa de investimento (\%PIB) $0 \leq \beta \leq 30$ $\theta$ - NFSP - variação da dívida líquida (\%PIB) $\quad 0 \leq \theta \leq 40$ $\varepsilon-$ Exportação FOB (\%PIB) $\quad 0 \leq \varepsilon \leq 18$

Utilizando a normalização na forma anteriormente apresentada, temos os novos índices associados à atuação do Governo:

$$
\begin{aligned}
& \alpha^{\prime}=\frac{5}{3} \alpha \\
& \beta^{\prime}=\frac{10}{3} \beta \\
& \theta^{\prime}=\frac{5}{2} \theta \\
& \varepsilon^{\prime}=\left(5+\frac{5}{9}\right) \varepsilon
\end{aligned}
$$

Assim, tomando os valores dessas variáveis no intervalo de um índice linear entre 0 e100, segue-se o Gráfico 2 (ver página seguinte).

A política governamental de expansão fiscal e monetária torna-se, portanto, evidente nesse novo quadrado mágico modificado. O Governo estimulou sensivelmente a expansão do crédito para consumo e investimento. Isso foi decorrente em parte da emissão de novos meios de pagamento e também do aumento dos gastos financiados pelo BNDES, entre os anos 2009 e 2010. A resposta brasileira nesse período garantiu uma demanda efetiva aquecida em um período de recessão mundial, somada a uma alta nas exportações devido ao comércio com o mercado chinês. Houve também um maior estímulo às exportações, ainda que o cenário recessivo global tenha tido uma influência mais contundente na redução das exportações em 2010 e 2011. Assim, podese pensar que a estratégia adotada consistiu 


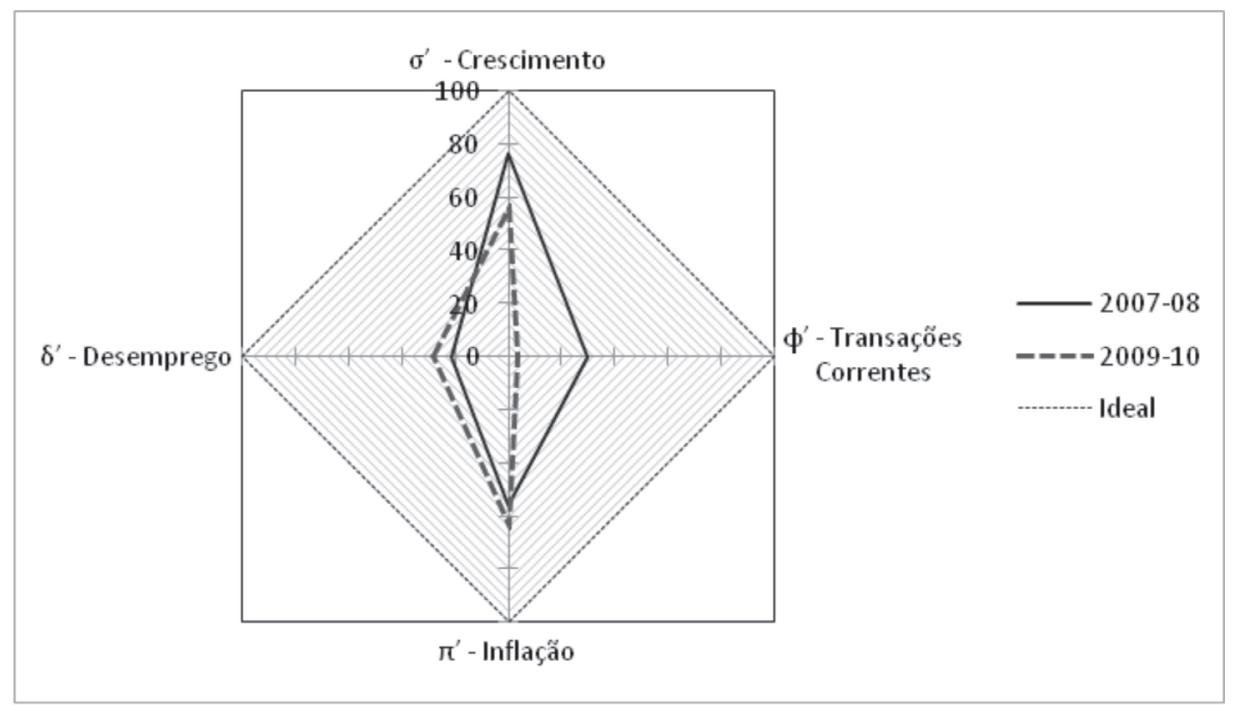

Fonte: Elaboração própria.

\section{Gráfico 1: Indicadores do Brasil}

Tabela 2: Quadrado modificado de Kaldor (médias dos períodos)

\begin{tabular}{l|c|c}
\hline & $\mathbf{2 0 0 7 - 0 8}$ & $\mathbf{2 0 1 0 - 1 1}$ \\
\hline Crédito & 33,95 & 45,14 \\
Investimento & 18,27 & 19,37 \\
Necessidade de financiamento do setor público (NFSP) & 16,74 & 18 \\
Exportação & 11,88 & 9,91 \\
\hline
\end{tabular}

Fonte: dados Ipeadata e Ministério do Desenvolvimento, Indústria e Comércio (MDIC).

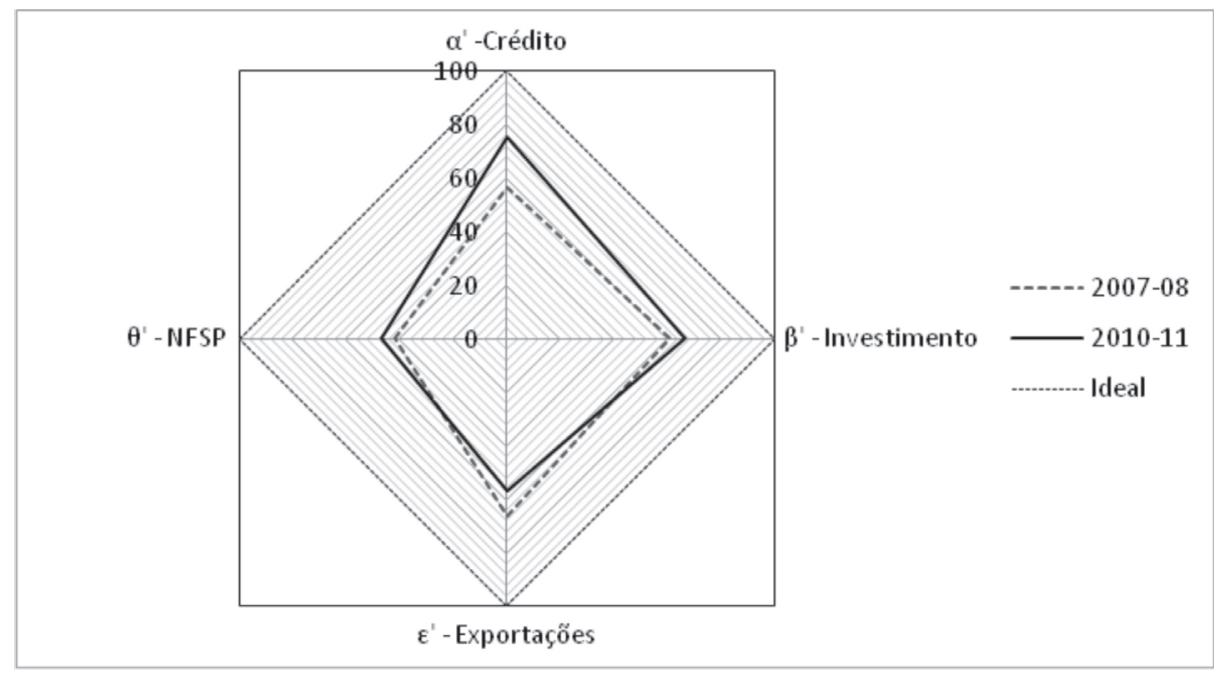

Fonte: Elaboração própria.

Gráfico 2: A atuação do Governo brasileiro 
em uma combinação de export-led growth e consumption-led growth, porém a frequência alta e certa inconsistência de intervenções do Governo em setores da infraestrutura (políticas petrolífera, energética e de transportes etc.) trazem incertezas para potenciais investidores, prejudicando o processo de acumulação de capital (MYRDAL, 1957; KALDOR, 1978).

Alguns acontecimentos positivos consistiram na crescente emissão de crédito, crescimento dos salários reais, políticas de transferência de renda etc., que permitiram a ascensão social de 40 milhões de brasileiros. Todavia, surge a necessidade de se garantirem condições que possibilitem o pagamento desses financiamentos, tais como o controle da inflação e uma adequada taxa de juros, que garanta a sustentabilidade dessa empreitada.

Por outro lado, o Governo tem usado incentivos, convencimento e pressão para impulsionar o investimento privado e reduzir os efeitos internos da crise internacional. Não tem ocorrido muito sucesso nessa área. Notemos que esses recursos estão sendo escassos e alocados sem uma melhora significativa na infraestrutura, e sem o rompimento dos entraves burocráticos que emperram os investimentos públicos e privados. A necessidade de planejar e gerar preços competitivos coloca em pauta a importância de termos um investimento produtivo mais eficiente, incorporando mudanças tecnológicas e exigindo maior fiscalização por parte das agências reguladoras. No curto prazo, o investimento responde por parcela relevante da expansão da demanda interna. Mas a expansão da demanda doméstica tem esbarrado na fraqueza do investimento. A médio e longo prazo, as consequências do baixo investimento (como proporção do PIB) são graves, pois afetam a capacidade de crescimento sustentável. Salientamos a importância da necessidade de um olhar governamental que não responsabilize apenas a recessão global pela timidez da inversão.

Existe uma controvérsia sobre as duas dinâmicas de crescimento, por estímulo às exportações e/ou por estímulo ao consumo. Para Kaldor, a indústria era o principal motor da economia, no sentido de contribuir para uma alocação mais eficiente dos recursos, introduzir novas tecnologias, estimular o processo de learn-by-doing, e favorecer o superávit na conta de transações. $\mathrm{O}$ estímulo às exportações tem sido uma rationale que vem desde os clássicos, e é favorecida por Kaldor. Entretanto, o sucesso das exportações está estritamente vinculado à demanda agregada dos países importadores. Além disso, Palley (2002) salienta que, na concorrência global, os países emergentes podem incorrer numa disputa de abaixar seus custos até o "fundo do poço". Nesse caso, fica claro o risco dessa estratégia, que pode ser prejudicada por instabilidades financeiras no mercado externo (investimento fortemente especulativo em períodos de recessão global).

No que tange à estratégia baseada no consumption-led growth, pode-se argumentar que, apesar das desejáveis mobilizações sociais para cima, nada garante que esse avanço na inclusão social seja continuamente sustentável. Um aumento da renda, subsidiado seja pelo salário ou pelo crédito, que não seja acompanhado de um aumento na produtividade poderá gerar uma pressão inflacionária e também inadimplência por parte dos tomadores de crédito.

A amplitude e sustentabilidade das duas estratégias podem ser questionadas, o que tem levado a considerações conhecidas como "hiperatividade paralisante": de fato, um tratamento keynesiano hiperativo 
do governo que não esteja sustentado por uma capacidade produtiva avançada não surte efeitos. Segundo Lamounier (2005), o País precisa ser justo com o seu passado de forma a determinar o seu presente. Tal fenômeno ocorre devido ao fato de que, ao longo do período em análise, parte significativa do investimento realizado no País foi baseado em capital especulativo ou foi alavancado por um cenário auspicioso, impulsionado pela demanda global por commodities e por um contexto internacional mais favorável vivenciado antes da crise. Adicionalmente, as descobertas de reservas de petróleo no pré-sal aumentaram o otimismo, e as políticas de inclusão social, juntamente com uma política fiscal expansionista, colaboraram para o dinamismo da economia brasileira. Porém, com a crise econômica, o País teve as suas perspectivas de crescimento frustradas e o nível de atividade econômica acabou por declinar.

Além disso, outras questões precisam ser respondidas: o interesse de quem, deve ser levado em consideração na implementação de políticas públicas? Quais interesses devem ou podem ser sacrificados? Certamente, esses dois pontos envolvem questões referentes à dominância e distribuição do poder entre diferentes grupos na economia nacional e global.

Em um panorama mais detalhado a respeito das políticas econômicas aplicadas no país, podemos entender com mais cuidado como ocorreu o desempenho da economia brasileira no período imediatamente anterior à crise e nos anos subsequentes.

\section{Políticas econômicas face à crise financeira internacional}

\section{Políticas pré-crise}

O Brasil passou por vários planos frustrados de estabilização da inflação até o projeto de implementação do Plano Real, quando se desenvolveu o conhecido tripé macroeconômico (superávit fiscal/metas de inflação/controle do câmbio). Porém, ficaram expostos flancos da balança comercial, em especial o desequilíbrio externo e o déficit fiscal. A sobrevalorização do câmbio gerou um déficit na balança comercial e no setor de serviços que tornou o país dependente do investimento direto estrangeiro. Embora a relação dívida

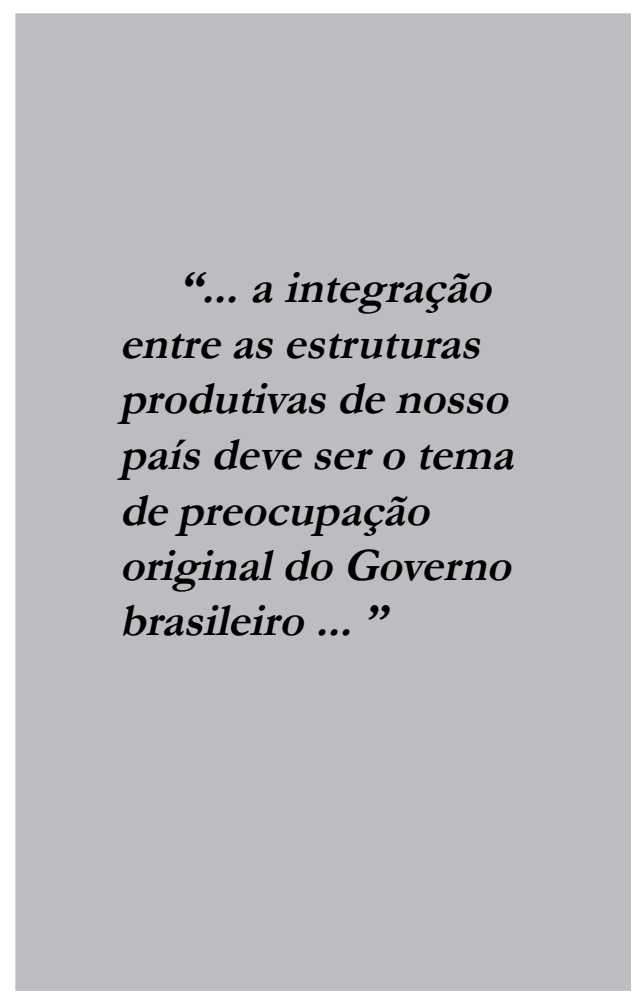

pública/PIB esteja diminuindo, esta não consegue ser saldada, apesar dos superávits primários ocorridos ao longo dos anos. Tal fenômeno ocorre porque, apesar do saldo positivo entre as despesas e receitas públicas, o resultado não é positivo o suficiente para cobrir os juros, razão pela qual surge déficit nominal. Essa retroalimentação da dívida pública se dá pelos juros altos, que sustentam o investimento direto 
estrangeiro responsável por compensar as nossas baixas sistemáticas da conta de serviços e rendas em nossa balança de pagamentos. Adicionalmente, como herança da política dos juros altos, os títulos da dívida pública emitidos apresentam rentabilidade tão alta que aplicar neles é mais lucrativo que o capital investido na produção, implicando em uma desestabilização do mercado financeiro e produtivo.

Temos, então, algumas das razões pelas quais o País apresentava, desde os anos 1990, várias trincheiras pelas quais uma crise externa poderia se alastrar. Essas trincheiras se deram pela variação brusca do câmbio, pelo preço das commodities e pela preferência de investimento no mercado especulativo. No que tange à entrada de recursos externos, não apenas estes se voltavam aos ativos especulativos de grande risco, como também estimularam, via apreciação da moeda nacional, o consumo de importados.

Nos últimos 15 anos, a elevada taxa de juros, mantida para evitar a fuga de capitais e tornar o rendimento de nossos títulos públicos um dos melhores do mundo, terminou por ajudar no controle do regime de metas da inflação. Não obstante, esse benefício também se deu com muitos custos à economia brasileira. A recusa da equipe econômica governamental em lidar com um modelo abrangente e dinâmico como o de industrialização kaldoriana deixou à margem elementos fundamentais para o desenvolvimento e a integração dos setores econômicos. A saber, o nível de investimento foi reduzido, sendo que, entre 2000 e 2008, essa taxa obteve uma média de $15,05 \%$, em contraste com a própria taxa de investimento da década perdida (anos 1980), que foi de $22,5 \%$.

O contraste entre a baixa taxa de investimento brasileira (ficando marginalizada em prol do equilíbrio da balança de pagamentos) e as dificuldades governamentais pelo controle da inflação revela uma questão particular da economia brasileira que não pode ser comparada aos seus parceiros emergentes. Nossa economia possui uma maior heterogeneidade entre suas estruturas produtivas com uma pauta de exportação voltada à venda de commodities. Ainda, o preço das suas exportações tende a se deteriorar em vista das diferenças das elasticidadesrenda da demanda de seus parceiros comerciais. Salientamos, pela perspectiva kaldoriana apresentada neste trabalho, que a integração entre as estruturas produtivas de nosso país deve ser o tema de preocupação original do Governo brasileiro, em vez de uma pequena faceta do cenário macroeconômico que poderia ser resolvida extraordinariamente com o controle dos juros e a estabilidade dos preços. Nesse sentido, fica clara a nossa escolha do quadrado mágico modificado de Kaldor (Gráfico 2), contendo simultaneamente as relações entre taxas de investimento, exportações, gasto governamental e emissão de crédito. Essas variáveis não devem ser consideradas secundárias na amplitude do cenário macroeconômico, mas sim as partes principais de um mecanismo governamental a ser examinado e analisado em conjunto.

O lento progresso na produtividade do trabalho acarreta contração da competitividade industrial e os termos de troca podem se tornar desfavoráveis aos países com uma pauta de exportações composta em grande parte pela agricultura; naturalmente, porque a elasticidade-renda das importações é sempre mais inelástica (Thirwall, 2003 e 2008). Portanto, todas essas deficiências impostas ao Brasil deixam nossa economia sujeita a ciclos reflexos, em que só é possível crescer se e quando a liquidez internacional é farta. 
Ainda, a sobrevalorização do câmbio real dificultava cada vez mais a inserção da produção doméstica na economia mundial. A moeda brasileira, no período pré-crise, estava relativamente sobrevalorizada por sua natureza financeira.

O Governo Lula trouxe uma nova transformação da economia, voltada a projetos sociais e à expansão do investimento. Contudo, decidiu dar continuidade a certos esforços realizados no Governo de Itamar Franco e depois no Governo de Fernando Henrique Cardoso, de maneira a prosseguir no patamar de investimento de baixo risco, que o país havia alcançado no mercado internacional. Para tanto, tentou manter firme o tripé controle cambial (agora com bandas)/metas de inflação/ austeridade fiscal (superávit). As medidas não foram suficientes para barrar a tormenta da crise de 2008, mas concederam ao País um cenário econômico singular para se tratar da crise nos anos seguintes.

Antes do deflagrar da crise, o País apresentava bons indicadores internos (veja a Tabela 3): crescimento e inflação moderados, déficit e endividamento inferior à média mundial, consumo e crédito em expansão, geração de empregos formais, aumento da massa salarial e redução da pobreza. No plano financeiro, pode-se perceber uma valorização intensa de ativos, uma apreciação na bolsa de valores, e uma demanda relativamente aquecida.

Essa conjuntura se deu no período imediatamente anterior à crise, porque em 2007 a política monetária continuou a tendência já aplicada de ser moderadamente flexibilizada para fazer frente a um cenário de aceleração de preços observado em 2006. No decorrer de 2007, reduções na taxa de juros se nortearam pela percepção posterior de que a alta dos preços era decorrente de fatores essencialmente transitórios. Por isso, apesar de o ambiente externo apresentar um cenário de menor liquidez e aumento da volatilidade dos mercados globais na segunda metade do ano, o Comitê de Política Monetária (Copom) brasileiro considerou que a evolução recente da inflação em patamar consistente com as metas era condizente

Tabela 3: Indicadores econômicos do Brasil e da América Latina

\begin{tabular}{|c|c|c|c|c|c|c|c|c|c|}
\hline & 2003 & 2004 & 2005 & 2006 & 2007 & 2008 & 2009 & 2010 & 2011 \\
\hline Crescimento Anual do PIB (\%) & 1,14 & 5,71 & 3,15 & 3,95 & 6,09 & 5,1 & $-0,32$ & 7,53 & 2,73 \\
\hline $\begin{array}{l}\text { Investimento direto estrangeiro } \\
\text { líquido, \% do PIB }\end{array}$ & 1,83 & 2,73 & 1,75 & 1,77 & 3,26 & 3,06 & $-1,94$ & 2,48 & 2,8 \\
\hline Transações Correntes, \%PIB & 0,75 & 1,76 & 1,585 & 1,25 & 0,11 & $-1,70$ & $-1,49$ & $-2,2$ & $-2,11$ \\
\hline $\begin{array}{l}\text { Exportações de bens e serviços } \\
\text { (crescimento, \% anual) }\end{array}$ & 10,39 & 15,29 & 9,33 & 5,04 & 6,19 & 0,54 & $-9,12$ & 11,51 & 4,4 \\
\hline $\begin{array}{l}\text { Importação de bens e serviços } \\
\text { (crescimento, } \% \text { anual) }\end{array}$ & $-1,620$ & 13,30 & 8,46 & 18,44 & 19,87 & 15,35 & $-7,59$ & 35,83 & 9,7 \\
\hline $\begin{array}{l}\text { Indústria, valor adicionado } \\
\text { (crescimento \% anual) }\end{array}$ & 1,31 & 7,84 & 2,07 & 2,16 & 5,31 & 4,0 & $-5,6$ & 10,41 & 1,52 \\
\hline Taxa de investimento & 15,28 & 16,1 & 15,94 & 16,43 & 17,44 & 19,11 & 18,07 & 19,46 & 19,29 \\
\hline Variação PIB Argentina (\%) & 8,83 & 9,02 & 9,17 & 8,46 & 8,65 & 6,75 & 0,85 & 9,16 & 8,86 \\
\hline Taxa de investimento Argentina & 15,1 & 19,1 & 21,4 & 23,3 & 24,2 & 23,2 & 20,9 & 22 & 22,5 \\
\hline Variação PIB Chile (\%) & 3,95 & 6,04 & 5,55 & 4,58 & 4,60 & 3,66 & $-1,03$ & 6,09 & 5,98 \\
\hline Taxa de investimento Chile & 22,1 & 20,8 & 23,2 & 21,1 & 21,2 & 25,9 & 20,2 & 23,5 & 24,6 \\
\hline Variação PIB México (\%) & 1,35 & 4,05 & 3,20 & 5,15 & 3,26 & 1,19 & $-5,95$ & 5,53 & 3,91 \\
\hline Taxa de investimento México & 22,8 & 24,6 & 23,7 & 26,2 & 25,5 & 26,9 & 23,8 & 24 & 25,2 \\
\hline
\end{tabular}

Fonte: World Bank Database e Ipeadata. 
com maiores reduções na taxa de juros. Assim, em outubro, a taxa de juros foi estabelecida em 11,25\% ao ano.

A condução da política monetária foi orientada de forma que a inflação se mantivesse dentro das metas estabelecidas. Isso também permitiu que o País absorvesse de forma suavizada as turbulências do mercado financeiro internacional, iniciadas a partir de meados de 2007, e contribuiu para que o aumento do dinamismo da demanda interna não se deteriorasse em resposta a um ambiente de elevação acentuada dos preços agrícolas.

Embora o crescimento dos níveis de demanda tenha contribuído para a redução dos superávits da balança comercial, o balanço de pagamentos obteve resultado global consistentemente positivo com recorde de US $\$ 87,5$ bilhões neste ano. Assim, os resultados favoráveis das contas externas permitiram a adoção de políticas mais consistentes para a administração do passivo externo líquido do País, cuja posição credora foi influenciada pelo aumento nas reservas internacionais e pela redução do estoque da dívida externa.

Essa estratégia de redução da exposição cambial do setor público e de recomposição das reservas, adotada desde 2003, conferiu maior solidez às contas externas do país e elevou a resistência da economia aos choques adversos externos, conforme pôde ser verificado pelo impacto marginal da crise no mercado subprime dos Estados Unidos sobre a economia brasileira neste ano. Com efeito, as reservas internacionais passaram de US $\$ 85,8$ bilhões em 2006 para US\$ 180,3 bilhões em 2007. Adicionalmente, o Tesouro Nacional continuou a sua política de aquisição de recursos no mercado de câmbio para o pagamento do serviço da dívida externa e de recompra antecipada de bônus soberanos a fim de fortalecer o perfil do endividamento.

Em síntese, a melhoria dos fundamentos macroeconômicos da economia brasileira, juntamente com o recorde alcançado pelas reservas internacionais, o aumento da corrente de comércio, a redução da dívida pública externa vinculada à exposição cambial e o fluxo recorde de divisas para o País, perfilaram entre os elementos fundamentais que conferiram maior solidez ao País em um contexto de forte instabilidade dos mercados financeiros internacionais. No que tange ao mercado financeiro doméstico, apesar da controvérsia exibida por uma taxa de juros que rivalizava com os investimentos produtivos e impactava desfavoravelmente as finanças públicas, houve uma grande quantidade de reservas, oriundas do sistema normativo e regulamentário do País. Este cumpria com folga os acordos de Basiléia, em que o coeficiente de capital mínimo exigido (patrimônio líquido em relação aos ativos dos bancos ponderados pelo risco) era muito superior ao já previamente exigido nos comitês econômicos no período pré-crise. Entretanto, a crise se alastrou para o País devido a outras fragilidades.

\section{Políticas pós deflagração da crise}

Em 2008, o desempenho da atividade econômica internacional passou a ser afetado de maneira mais acentuada pelos desdobramentos da crise oriunda do mercado subprime nos EUA. Deste abalo econômico, a manifestação inicial mais intensa no Brasil (porém não a única) foi a depreciação do real, um sintoma da escassez global de dólares e da piora dos termos de troca decorrente dos preços das commodities. A queda do preço das commodities também engendrou a redução do comércio. Em 
outubro de 2008, a moeda brasileira foi uma das primeiras a serem abandonadas pela contração de liquidez, o que ocasionou a variação brusca de $\mathrm{R} \$ 1,60 /$ dólar em agosto de 2008 para $\mathrm{R} \$ 2,30 /$ dólar em outubro de 2008.

Na opinião de Silva e Resende (2008), nos períodos de reversão cíclica do nível de liquidez (isto é, uma crise), o racionamento de crédito tende a ser muito maior para as economias em desenvolvimento. Portanto, a tendência do esgotamento de divisas externas, em um mercado liberalizado, tende a ser muito mais provável nos países em desenvolvimento do que em países desenvolvidos com um mercado financeiro consolidado.

Nesse sentido, para fazer frente a um cenário global marcado por escassez de crédito e indícios de uma crise muito maior nos investimentos produtivos externos de nossa nação, o Governo brasileiro decidiu interromper a trajetória de aumento dos juros praticada no início do ano e passou a praticar uma política monetária mais flexível, fixando a taxa de juros em 13,75\% no final de 2008.

A economia brasileira, após ter apresentado um cenário de expansão do consumo e do investimento na maior parte do ano, passou a evidenciar no segundo trimestre os impactos do acirramento da crise financeira internacional. Esses impactos foram sentidos fortemente no crédito e nas expectativas dos agentes. Nesse novo cenário de redução do nível da atividade econômica, as principais políticas contracíclicas aplicadas na área monetária se direcionaram para a expansão do crédito, com o objetivo de garantir as exportações e a liquidez no mercado por meio de empréstimos pelo Banco Central em moeda estrangeira, e para a liberação de recursos, com a finalidade de regularizar a liquidez do sistema financeiro nacional e incentivar o crescimento dos empréstimos.

No que se referem ao setor externo, as transações correntes, após apresentarem resultados superavitários por cinco anos consecutivos, registraram déficit em 2008. Esse resultado negativo se aprofunda até a última medição em 2011 e se deve ao fato de o crescimento das importações superar as exportações e ao aumento nas remessas líquidas de lucros e dividendos. A grave

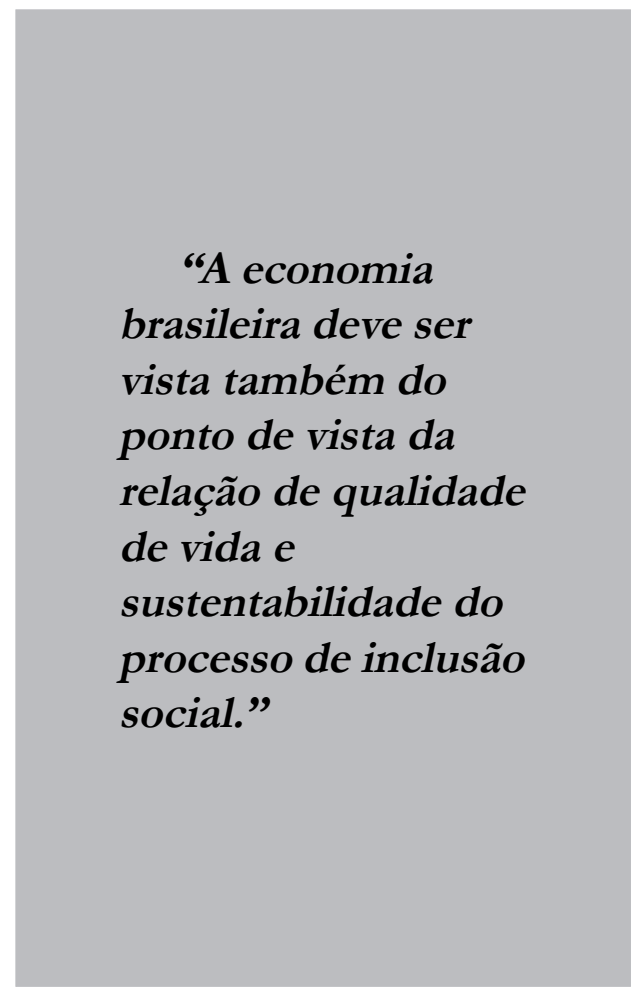

reversão da balança comercial foi um dos principais fatores relacionados à queda da performance do País, como pode ser visto no quadrado mágico exibido no Gráfico 1. Os efeitos do cenário econômico internacional sobre o crédito também fizeram com que o Banco Central tomasse medidas no mercado de câmbio por meio de intervenções de compras de dólar no mercado 
spot. Convém destacar que, mesmo em um cenário de deterioração dos mercados financeiros, as reservas internacionais cresceram e atingiram ao final do ano US $\$$ 206,8 bilhões.

Quanto ao setor bancário, as repercussões da crise foram diferentes do ocorrido internacionalmente em vista da diferente natureza bancária que o Brasil vinha desenvolvendo desde os anos 1990. Há um boom de crédito desde 2004, destacando-se o crédito pessoal, financiamento a veículos e capital de giro das empresas, entre outros. Apesar da brusca redução do spread bancário após o deflagrar da crise, ele ainda permaneceu elevado, permitindo aos bancos obter elevada lucratividade.

Entretanto, as instituições bancárias de menor porte sofreram uma contração de liquidez mais abrupta do que os grandes bancos, inclusive em moeda nacional. Um termo cunhado para sintetizar esse caso é "empoçamento de liquidez" (Mesquita e Torós, 2010). Nessas condições, o Banco Central decidiu agir ativamente ao estabelecer um regime que liberasse mais liquidez para os pequenos bancos, e permitir que bancos maiores pudessem comprar os ativos dos primeiros. Essas mudanças no período pré-crise alteraram significativamente a arquitetura do mercado bancário brasileiro.

No que concerne à atuação da equipe econômica do Governo e não às normativas do Banco Central, as medidas de combate à crise surgiram por vários instrumentos. Em 2009 o acirramento do cenário recessivo nos mercados financeiros demandou medidas adicionais nas esferas monetária, fiscal e cambial pelo Governo brasileiro. Basicamente, o objetivo das políticas econômicas adotadas consistia em oferecer melhores condições de liquidez interna e proporcionar estímulos à demanda agregada que favorecessem a retomada do crescimento.

A política monetária foi flexibilizada por meio de sucessivos cortes na taxa de juros, que terminou por ser fixada em $8,65 \%$ em 2009. Na área fiscal, foi mantida e ampliada a política de redução de impostos sobre produtos industrializados incidentes sobre eletrodomésticos, automóveis, produtos da construção civil, móveis e bens de capital. Essas medidas visavam a assegurar a estabilidade relativa do nível de emprego nesses segmentos intensivos em mão de obra, e a fortalecer o dinamismo da demanda doméstica.

No que concerne ao setor externo, a atuação do Governo se concentrou na criação de instrumentos para assegurar liquidez em moeda estrangeira frente à continuada escassez de crédito internacional. Os efeitos recessivos da crise financeira sobre a economia mundial acabaram por contribuir para a continuidade do resultado deficitário em transações correntes. Nesse contexto, o PIB registrou variação negativa e terminou o ano $\mathrm{em}$ $-0,32 \%$. A inflação terminou o ano com variação de 4,31\%, pressionada pelo aumento dos preços dos alimentos e das políticas econômicas mais expansionistas levadas a efeito pelo Governo. Contudo esse limite esteve situado dentro do intervalo de tolerância do regime de metas para a inflação.

Em 2010, os mercados financeiros internacionais registraram menor volatilidade do que no ano anterior. Porém, presenciava-se um contexto de forte pressão sobre as cotações das commodities agrícolas a partir do segundo semestre do ano, o que impactou diretamente o crescimento da taxa de inflação e o processo de condução da política monetária. Nesse sentido, o Copom, após manter a taxa de 
juros (Selic) em 8,75\% ao ano, terminou o período praticando uma política monetária mais restritiva com uma taxa de 10,75\% .

Adicionalmente, o Governo adotou, no final do ano, um conjunto de medidas de natureza macroprudencial com o objetivo de aperfeiçoar os instrumentos de regulação, assegurar a estabilidade do sistema financeiro nacional e permitir a continuidade do desenvolvimento sustentável do mercado de crédito. Entre as principais medidas estão a elevação dos depósitos compulsórios e o requerimento de capital para operações de crédito a pessoas físicas com prazos superiores a 24 meses.

No setor externo, foram adotadas políticas que objetivaram criar condições favoráveis para o aumento da competitividade das exportações brasileiras. A condução da política cambial foi orientada por medidas que evitavam que a liquidez em moeda estrangeira resultasse em excessiva volatilidade e desequilíbrios no mercado de câmbio. Apesar das incertezas quanto à efetiva melhora do cenário internacional, o processo de fortalecimento da economia brasileira se traduziu em um crescimento de $7,5 \%$ no ano.

A economia brasileira moderou a expansão em 2011, após o expressivo resultado registrado no ano anterior. Essa evolução esteve alinhada com o cenário de deterioração do ambiente econômico internacional, mobilidade social das classes $\mathrm{D}$ e $\mathrm{C}$ e os ciclos de expansão do crédito. Como resultado, o PIB registrou aumento de $2,7 \%$ no ano.

Entretanto, é importante ressaltar que, em um ambiente de retração da demanda externa, o crescimento da economia foi sustentado pelo mercado doméstico, com destaque para o dinamismo do consumo das famílias. Esse desempenho da demanda doméstica refletiu principalmente as condições favoráveis do mercado de trabalho e a manutenção dos programas governamentais de distribuição de renda.

A política de fortalecimento da demanda interna foi em sua maioria impulsionada por linhas de crédito, com grande participação do BNDES. Nesse sentido, em nosso quadrado mágico das atuações governamentais (Gráfico 2), torna-se evidente o dilema kaldoriano entre consumption-led growth (aqui coordenado com o crédito) e export-led growth. As principais variáveis que sinalizam o melhor desempenho do Governo brasileiro estão associadas ao eixo vertical crédito-exportações.

A redução do nível da atividade econômica ao longo de 2011 também foi compatível com as políticas econômicas aplicadas desde 2010, visando a ajustar as condições de liquidez interna e o descompasso entre a oferta e a demanda agregadas. Com vistas a acomodar a perspectiva de consolidação de um cenário inflacionário, causado tanto pelo crescimento da demanda interna quanto pelo aumento do preço das commodities, o Copom promoveu até meados do ano elevações na taxa de juros, que foi fixada em $12,5 \%$ ao ano em julho. O trabalho de Silva e Harris (2012) trata do tema.

Contudo, no decorrer dos demais meses, ante um cenário internacional cada vez mais restritivo, e devido aos recuos no nível de capacidade instalada da economia, o Copom procedeu a sucessivos cortes na taxa de juros, que chegou a $11 \%$ ao ano. Assim, apesar do fraco desempenho da economia brasileira nesse ano, a relativa solidez das contas externas brasileiras neutralizou o impacto da volatilidade dos mercados financeiros internacionais.

Nesse sentido, a consistência da política macroeconômica brasileira, baseada nos pilares metas de inflação, responsabilidade fiscal e câmbio flutuante, possibilitou 
alguma resistência aos choques adversos derivados da crise financeira internacional. Porém, visualizando o quadrado mágico exposto no Gráfico 1, pode-se constatar que houve contração dos indicadores econômicos (observa-se isso nos losangos) entre os dois períodos, exceto no eixo referente à taxa de desemprego. No Gráfico 2, percebe-se a forte intervenção governamental (em 2009-2010) na direção de um melhor desempenho por meio da agenda do consumo e gasto governamental. Quanto às exportações, não fomos tão bem-sucedidos.

Analisando conjuntamente os resultados apresentados nos dois quadrados mágicos, nota-se que a ênfase governamental está nos indicadores econômicos e a variável que causa maior preocupação é aquela referente à taxa de crescimento da economia. Faz sentido argumentar que o crescimento do PIB não contém informação relevante sobre aspectos sociais no desempenho da economia. Segundo Delfim Netto (2012): “o que importa é o crescimento econômico com a inclusão social. Temos crescido menos, mas a inclusão continuou".

Contudo, é necessário ter cuidado para evitar a estagnação do PIB com tendência da economia para o pleno emprego, pois tal situação dificultará a sustentabilidade do processo de inclusão social. Além disso, diversos economistas têm ressaltado a necessidade de evitar artifícios contábeis na implementação da política econômica. Tais exercícios de alquimia não geram efeitos sustentáveis, ademais podem ter um custo político devastador, pois geram insegurança e aprofundam as incertezas e desconfianças quanto à seriedade dos policy makers.

\section{Conclusão}

A partir da análise dos quadrados mágicos, é possível evidenciar que o impacto da crise não se constituiu em simples "marolinha" como suposto por certos economistas e governantes. $\mathrm{Na}$ verdade, a esperança de promover a recuperação sustentada no Brasil de modo a obter relativo sucesso na taxa de crescimento da economia, assim compartilhado com aquele obtido pela maioria dos países emergentes na América Latina, não resultou no esperado. Notemos que a taxa de crescimento do produto contraiu de 7,3\% em 2010 para 2,7\% em 2011, terminando em $1 \%$ em 2012. A balança comercial brasileira teve em 2012 seu pior resultado em 10 anos, sendo que a diferença entre as exportações e importações só não foi mais profunda porque se reduziram as importações, devido ao baixo PIB que diminuiu as compras externas brasileiras de insumos. O desempenho medíocre nas exportações do país se deve parcialmente à desaceleração do comércio mundial. A China, principal parceiro comercial do Brasil, reduziu suas importações em 7\%. A Argentina contraiu suas importações de produtos brasileiros em 20,7\%. Notemos que, no caso da Argentina, o destino de nossas exportações era predominantemente de bens manufaturados. A taxa de inflação tem permanecido acima do centro da meta e a conta corrente do balanço de pagamentos não tem melhorado. Contudo, a taxa de desemprego tem sido surpreendentemente baixa.

Que julgamento pode-se fazer da presente situação? Diversos economistas argumentam que, embora o governo venha mantendo inúmeros estímulos, essa hiperatividade tem aspectos conflitantes. Além disso, são essencialmente pontuais, uma vez que não focam os conhecidos obstáculos estruturais ao crescimento sustentável, especialmente no que tange ao investimento produtivo. Soares (2012) salienta o 
problema da atual desindustrialização relativa para enfatizar problemas estruturais do País: endividamento das famílias, baixo crescimento da produtividade, baixo investimento público e privado, infraestrutura deficiente, entre outros. Todas essas debilidades são crônicas, e apresentam uma gravidade potencial no contexto da crise internacional. Assim, fica caracterizada a importância de se repensar a política de desenvolvimento econômico, levando em conta a demanda mundial em direção dos mercados mais dinâmicos, entre os quais os mercados das economias emergentes.

No debate entre consumption led-growth e export-led growth, o Brasil escolheu uma combinação de medidas. Ao se revisitar os quadrados mágicos, não pretendemos somente mostrar um referencial da atual conjuntura brasileira, mas salientar também a importância da aplicação simultânea de metas e instrumentos que não possuam um único vértice de ajuste. A abordagem deve ter uma especificação (natureza) multidimensional. Afinal, a política macroeconômica não deve estar voltada somente para a estabilidade de preços, mas deve contemplar também o crescimento, a distribuição funcional de renda, o pleno emprego, e a combinação de equilíbrio interno (estabilidade e crescimento econômico) e equilíbrio externo (sustentabilidade do balanço de pagamentos). Consideramos que a visão da equipe econômica governamental não tem facilitado a superação da crise e a preparação do País para um futuro melhor. Prova disso é o insucesso no regime de metas de inflação em 2010, com diversos efeitos colaterais negativos que prejudicaram o desempenho da economia. Esses efeitos, que ocorreram nessa circunstância histórica, na verdade deveriam ser contemplados numa visão dinâmica e de longo prazo pelas políticas do Governo, e não como pequenos desvios não antecipados de trajetória. As autoridades econômicas deveriam melhor aproveitar as oportunidades para ajustar dinamicamente a trajetória de nossa economia, envolvendo no processo a expansão do investimento e do progresso tecnológico, bem como a desburocratização.

Certamente, a aplicação simultânea das duas estratégias divide as benesses e os riscos de ambas; seja em parte pela dependência do mercado externo, ou devido às pressões inflacionárias domésticas. Naturalmente, a escolha dessas estratégias não deixa de ser vinculada à pressão exercida por certos grupos de poder, potencializando o efeito de comparações de nosso desempenho com o de outros países emergentes, que envolvem certos juízos de valor. A economia brasileira deve ser vista também do ponto de vista da relação de qualidade de vida e sustentabilidade do processo de inclusão social. Sem uma perspectiva dinâmica e sustentável de crescimento e distribuição, estaríamos mais uma vez fadados a percorrer a esmo "em busca do tempo perdido", e nos distanciando do padrão de desenvolvimento socioeconômico desejado.

Ao apresentar a análise kaldoriana, não só avaliamos o desempenho geral de nosso país como também salientamos a necessidade de políticas integradas com os preceitos macroprudenciais e voltadas à demanda. Embora os quadrados mágicos sejam referenciais teóricos importantes para o estabelecimento de metas e instrumentos operacionais para a política econômica e social, eles perdem relevância se forem implementadas políticas inconsistentes. Se as metas e os instrumentos funcionarem adequadamente, o Governo ganhará credibilidade, atenuará o custo dos ajustes e reduzirá as incertezas sobre novos 
surtos de crise. Caso contrário, ocorrerão turbulências e apresenta-se a perspectiva de problemas futuros com amplas dificuldades na compatibilização do equilíbrio interno com o equilíbrio externo.

É importante salientar as dificuldades, dilemas e conflitos na busca por garantir a prosperidade compartilhada. Pode-se argumentar que, às vezes, as políticas econômicas utilizadas podem ser muito consistentes para serem inteligentes; outras vezes, muito inteligentes para serem consistentes; e, finalmente, nem consistentes nem inteligentes. Afinal, estamos na presença de incertezas e riscos nesse conturbado modo de produção. As fragilidades de propostas e a dificuldade de implementação de políticas econômicas pertinentes decorrem também do labirinto de pressões contraditórias que requerem discernimento, competência e sustentação política. Apenas assim reduziremos insucessos e poderemos ter uma efetiva revitalização de nossa economia.

Em síntese, a partir do nosso ensaio, percebe-se que o Brasil necessita, dentro do arcabouço teórico estudado, se esforçar para promover e incentivar a expansão da renda, o investimento produtivo e a exportação, buscando produzir bens que tenham maior elasticidade-renda da demanda, maior produtividade e melhor encadeamento produtivo e economias de escala (Thirwall, 2008). Nesse sentido, os esforços governamentais devem estar centrados na adoção de políticas industriais adequadas. Entre elas destacamos um câmbio competitivo, melhorias na infraestrutura, proteção comercial orientada para promover melhorias na exportação e a melhoria estrutural necessária para o desenvolvimento sustentável.

(Artigo recebido em janeiro de 2013. Versão final em junho de 2013).

\section{Notas}

* Os autores agradecem a Cristiane Soares, Wellington Carlos e Rodolfo Marcílio Teixeira pela colaboração no desenvolvimento desse trabalho.

${ }^{1}$ Seu argumento é que, no longo prazo, não há substituto para a ênfase na exportação de bens manufaturados. Nesse caso, tanto o consumo quanto o investimento podem expandir simultaneamente, eliminando um dilema aparente. Essas exportações são um componente da demanda agregada que gera saldo na balança comercial e potencializa maiores investimentos estrangeiros. Veja Targetti \& Thirwall (1989), introdução, pp. 19 e 20.

${ }^{2}$ Com referência a esses tópicos ver, por exemplo, Bhaduri e Marglin (1990), Bhaduri (2008), O’ Hara (2009).

${ }^{3}$ A esse respeito, convém ressaltar que a tese de Myrdal sobre a teoria circular de causação acumulativa (Myrdal's thesis of cumulative causation - 1957) não é idêntica à de Kaldor. A visão de Myrdal tem muito em comum com a perspectiva estruturalista de economistas latino-americanos, ligados à CEPAL. Observe que para Hunt (1989, p. 59): “This was quite quickly recognised, and as such his perspective on underdevelopment came to be regarded as complementary to other structuralist analyses and, thus, part of the corpus of structuralist literature". Portanto, Hunt não faz qualquer menção a Kaldor como membro da escola estruturalista. Contudo, 
analisando a contribuição de Kaldor (1972), Hunt (1989, p.318) argumenta que: "In place of an irrelevant notion of general equilibrium, Kaldor proposes the reinstatement of the 'theorem of endogenous and cumulative change' ... and revived in the 1950s by the development economist Gunnar Myrdal, who called it 'the principle of cumulative causation'.” Fundamentalmente, Myrdal estava usando o conceito como base para tratar do processo de desenvolvimento econômico, enquanto Kaldor usou o conceito em uma perspectiva mais ampla, como uma crítica fundamental à teoria neo-clássica do equilíbrio geral.

${ }^{4}$ Note que Kaldor está também preocupado com conflitos e "trade offs" nos objetivos e metas para a política econômica. Nos quadrados mágicos, representados na Figura 1, inflação e desemprego são plotados com o eixo invertido, porque quanto maior os seus valores, pior é a performance do País (são negativamente correlacionados). Quanto à inflação, acreditamos que se ela for relevada isso irá gerar uma série de distorções na economia.

${ }^{5}$ Analogamente, aqui as variáveis tiveram seu limite máximo determinado pelo desempenho do País na última década. No que tange à taxa de investimento, nos permitimos estender além o índice máximo (ótimo). Tivemos como perspectiva o exemplo do México, que conseguiu obter a taxa de 25,2\% no período 2005-11, segundo o Valor Econômico, outubro de 2012.

\section{Referências bibliográficas}

Bhaduri, Amit. On the dynamics on profit - led and wage - led growth. Cambridge Journal of Economics, v.32, n.1, p. 147-160, 2008.

Bhaduri, Amit; Marglin, Stephen. Unemployment and the real wage: the economic basis for contesting political ideologies. Cambridge Journal of Economics, v.14, n.4, p. 375393, 1990.

Bernard, Michel; Drouet, Michel; Echaudemaison, Claude-D; Pinet, Nicole. Economie et Societé Françaises. Paris: Édition Nathan, 1988.

Delfim Netro, Antônio. Honestidade nas comparações. Carta Capital. Disponível em:http://www.cartacapital.com.br/economia/honestidade-nas-comparações/. Acesso em: 7 dez. 2012.

Hunt, Diana. Economic theories of development: an analysis of competing paradigms. Harvester Wheatsheaf: Hertfordshire, England, 1989.

KaLdor, Nicholas. Conflicts in national economic objectives. Economic Journal, v. 81, N. 321, p. 1-16, mar. 1971.

. The irrelevance of equilibrium economics. Economic Journal, December, 1972.

Causes of the Slow Rate of Economic Growth in the United Kingdom, Cambridge, UK: Cambridge University Press; reprinted in N. Kaldor (ed.) Further Essays on Economic Theory, New York: Holmes \& Meier Publishers, 1978.

KaLECKI, Michal. Three ways to full employment. The economics of full employment. Basil Blackwell Oxford. Oxford, 1944. 
Os aspectos políticos do pleno emprego. In: Miglioli, Jorge (Org.). Crescimento e Ciclo das Economias Capitalistas. São Paulo: Hucitec, 1977.

Lamounier, Bolívar. Da independência a Lula: dois séculos de política brasileira. Ed. Augurium, Universidade do Texas, 2005.

Medrano-B, René; Teixeira, Joanílio. Macroeconomic performance: revisiting a kaldorian perspective. Texto para Discussão, Universidade de Brasília, Departamento de Economia, n. 362, 2012.

Mesquita, Mário; Torós, Mário. Considerações sobre a atuação do Banco Central na crise de 2008. Banco Central do Brasil, Trabalhos para discussão -202. março de 2010.

MYrDAL, Gunnar. The principle of circular and cumulative causation, chapter 2. In MYRDAL, Gunnar. Economic Theory and Under-developed Regions. London: Methuen \& Co Ltd, 1957.

. Economic theory and underdeveloped countries. Duckworth, 1957.

O'HARA, Phillip. The principle of circular and cumulative causation: Myrdal, Kaldor and Contemporary Heterodox Political Economy. In BERgER, Sebastian (Ed.). The Foundations of Non-Equilibrium Economics: The Principle of Circular and Cumulative Causation. p. 91-105, Oxon and New York, Routledge, 2009.

PAlley, Thomas. A new development paradigm: domestic-demand-led growth: why it is needed \&how to make it happen. Foreign Policy in Focus, Sep. 2002.

Silva, Luiz; Harris, Ricardo. Sailing through the global financial storm: Brazil's recent experience with monetary and macropudential policies to lean against the financial cycle and deal with systemic risks. Working Paper Series, Banco Central do Brasil, n. 290, ago. 2012.

Silva, Guilherme Costa Jonas; Resende, Marco Flávio. A crise está aí, e agora? In: Dossiê da Crise, Associação Keynesiana Brasileira, Novembro de 2008.

SOARES, Cristiane. O modelo de balaço de pagamentos restrito e desindustrialização: teoria e evidências para ocaso brasileiro. Tese de doutorado, Departamento de Economia, Universidade de Brasília, 2012.

Teixeira, Joanílio; Araújo, Ricardo. A multi-sector version of the post-keynesian growth model. Proceedings of the Conference in Honour of Luigi L. Pasinetti. The Economics of Structural Change. Theory Institutions and Policy; Cambridge Political Economy Society, Cambridge: Setembro de 2012.

Targetti, Ferdinando; Thirlwall, Anthony P. The Essential Kaldor. London: Gerald Duckworth \& Co. Ltd, 1989.

Thirlwall, Anthony. P. The balance of payments constrains an explanation of international growth rates differences. Banca Nazionale Del LavoroQuaterly Review, n. 128, 1979.

. Trade, the balance of payments and exchange rate policy in developing countries. v. 1, n. 2, p. 131-144, Cheltenham, UK. Edward Elgar, 2003. . Trade liberalization and the poverty nations. Edward Elgar, 2008. 


\section{Resumo - Resumen - Abstract}

Política econômica brasileira frente à crise mundial recente: uma análise baseada nas contribuições de Kaldor

Joanílio Rodolpho Teixeira, Danielle Sandi Pinheiro e Paula Felix Ferreira

Neste trabalho avaliamos os resultados macroeconômicos recentes da economia brasileira por meio de um instrumental analítico baseado em uma extensão geométrica e algébrica do artigo seminal de Kaldor (1971), que levou à criação do quadrado mágico. Essa abordagem permite a comparação do desempenho pré-crise (2007-2008) e durante a crise (2009-2010). Nossa análise levanta algumas dúvidas sobre as medidas de política econômica adotadas na busca por contornar a presente crise e reduzir obstáculos estruturais no processo de desenvolvimento econômico no Brasil. Concluímos que a complexidade da gestão macroeconômica tem sido subestimada. No que tange às estratégias econômicas, nossa abordagem está centrada na controvérsia entre export-led growth vs consumption-led growth.

Palavras chave: quadrado mágico; controvérsia Kaldoriana; gestão governamental; crise econômica

\section{Política Económica Brasileña y la Reciente Crisis: una Análisis Basado em las Contribuciones de Kaldor \\ Joanilio Rodolpho Teixeira, Danielle Sandi Pinheiro y Paula Felix Ferreira}

En este artículo evaluaremos el resultado macroeconômico reciente de la economia brasileña, por medio de un instrumento analítico en una extensión del trabajo seminal de Kaldor (1971), que condujo a lacreación del Cuadrado Mágico. Esta perspectiva permite la comparación de los indicadores anteriores (2007-2008) y durante (2009-2010) la crisis. Nuestro análisis plantea dudas sobre la política econômica adoptada por el gobierno, en el anhelo de aplacar la crisis actual y reducir los obstáculos estrutucturales em el proceso de desarrollo econômico brasileño. Concluimos que la complejidad de la gestión macroeconómica ha sido subestimada. En lo que toca a las estratégias economicas, nuestro enfoque se centra en el controverso tema de export-led growth vs. consumption-led growth.

Palabras clave: cuadrado mágico; controversia Kaldoriana; gestión económica; crisis económica

Brazilian Economic Policy and the recent world crisis: an analysis based on the contributions of Kaldor

Joanilio Rodolpho Teixeira, Danielle Sandi Pinheiro and Paula Felix Ferreira

In this paper we assess the recent macroeconomic results of the Brazilian economy through an analytical instrument based upon an extension of Kaldor's seminal work (1971), the "Magical Square". This approach allows us to compare the performance pre-crisis (2007-2008) and during the crisis (2009-2010). Our analysis casts doubts on the economic policy implemented by the government to address the present crisis and to reduce long-standing structural obstacles to Brazil's economic developments. We conclude that the complexities of macroeconomic management have been underestimated. Concerning the common strategies applied on this crisis, our study is based on the export-led growth and consumption-led growth controversy.

Keywords: magical square; Kaldorian controversy; economic management; economic crisis 
Joanílio Rodolpho Teixeira

Professor Emérito. Departamento de Economia, Universidade de Brasília. Pesquisador 1A do CNPq. Contato: joanilioteixeira@hotmail.com

Danielle Sandi Pinheiro

Doutora e Mestre em Economia. Professora Adjunta do Departamento de Administração, Universidade de Brasília. Pesquisadora membro do Grupo de Pesquisa "Crescimento e Distribuição” do CNPq. Contato: danielle.sandi@gmail.com Paula Felix Ferreira

Pós-graduação no Departamento de Economia, Universidade de Brasília. Contato: paulafelixf@gmail.com 